\title{
Effects of Early Cranioplasty on the Restoration of Cognitive and Functional Impairments
}

\author{
Byung Wook Kim, MD ${ }^{1}$, Tae Uk Kim, MD, PhD ${ }^{1}$, Jung Keun Hyun, MD, PhD ${ }^{1,2,3}$ \\ ${ }^{1}$ Department of Rehabilitation Medicine, Dankook University College of Medicine, Cheonan; \\ ${ }^{2}$ Department of Nanobiomedical Science \& WCU Research Center, Dankook University, Cheonan; \\ ${ }^{3}$ Institute of Tissue Regeneration Engineering (ITREN), Dankook University, Cheonan, Korea
}

\begin{abstract}
Objective To delineate the effect of early cranioplasty on the recovery of cognitive and functional impairments in patients who received decompressive craniectomy after traumatic brain injury or spontaneous cerebral hemorrhage.

Methods Twenty-four patients who had received cranioplasty were selected and divided according to the period from decompressive craniectomy to cranioplasty into early ( $\leq 90$ days) and late ( $>90$ days) groups. The Korean version of the Mini-Mental State Examination (K-MMSE), Korean version of the Modified Barthel Index (K-MBI), and Functional Independence Measure (FIM) were evaluated at admission just after decompressive craniectomy and during the follow-up period after cranioplasty.

Results Twelve patients were included in the early group, and another 13 patients were included in the late group. The age, gender, type of lesion, and initial K-MMSE, K-MBI, and FIM did not significantly differ between two groups. However, the total gain scores of the K-MMSE and FIM in the early group (4.50 \pm 7.49 and $9.42 \pm 15.96$, respectively) increased more than those in the late group ( $-1.08 \pm 3.65$ and $-0.17 \pm 17.86$, respectively), and some of K-MMSE subscores (orientation and language) and FIM subcategories (self-care and transfer-locomotion) in the early group increased significantly when compared to those in the late group without any serious complications. We also found that the time to perform a cranioplasty was weakly, negatively correlated with the K-MMSE gain score $(\mathrm{r}=-0.560)$.

Conclusion Early cranioplasty might be helpful in restoring cognitive and functional impairments, especially orientation, language ability, self-care ability, and mobility in patients with traumatic brain injury or spontaneous cerebral hemorrhage.
\end{abstract}

Keywords Decompressive craniectomy, Stroke, Traumatic brain injuries, Cognition, Recovery of function

Received August 2, 2016; Accepted September 13, 2016

Corresponding author: Jung Keun Hyun

Department of Rehabilitation Medicine, Dankook University College of Medicine, 201 Manghyang-ro, Dongnam-gu, Cheonan 31116, Korea. Tel: +8241-550-6641, Fax: +82-41-551-7062, E-mail: rhhyun@dankook.ac.kr

ORCID: Byung Wook Kim (http://orcid.org/0000-0002-9456-9294); Tae Uk Kim (http://orcid.org/0000-0001-9904-8781); Jung Keun Hyun (http://orcid. org/0000-0001-9254-4424).

@ This is an open-access article distributed under the terms of the Creative Commons Attribution Non-Commercial License (http://creativecommons.org/ licenses/by-nc/4.0) which permits unrestricted noncommercial use, distribution, and reproduction in any medium, provided the original work is properly cited. Copyright $\odot 2017$ by Korean Academy of Rehabilitation Medicine 


\section{INTRODUCTION}

Decompressive craniectomy is a surgical procedure that reduces a high refractory intracranial pressure (ICP) after a traumatic brain injury, malignant ischemic stroke, subarachnoid hemorrhage, intracranial hemorrhage or acute subdural hematoma [1-4], and it is effective in lowering uncontrollable ICP and improving oxygen delivery to the brain [5-7]. However, in some cases, a decompressive craniectomy might result in impairments of the cerebral blood flow and glucose metabolism and alteration of cerebrospinal fluid circulation $[8,9]$. Therefore, cranioplasty should be followed by decompressive craniectomy to treat or prevent complications as well as for cosmetic purposes [8,10-16].

The appropriate timing for cranioplasty after decompressive craniectomy still has not be defined. Some previous studies have shown that early cranioplasty within 2-3 months after decompressive craniectomy increased the complication rates [17-19], and other studies reported no relationship between early cranioplasty and the rate of complications [20-25]. Some studies have also reported improvement in functional outcomes after early cranioplasty in patients with traumatic brain injury $[10,16,26]$, but others found no difference in functional outcomes between patients who received early cranioplasty and those received late cranioplasty $[11,17,22,27,28]$.

Here, we delineate the effects of early cranioplasty on the recovery of cognitive and functional impairments after decompressive craniectomy in patients with traumatic brain injury or spontaneous cerebral hemorrhage.

\section{MATERIALS AND METHODS}

\section{Subjects}

We performed a retrospective study for patients with traumatic brain injury or spontaneous cerebral hemorrhage who had undergone cranioplasty after decompressive craniectomy and had not received brain lobectomy. This study was approved by the Dankook University Hospital Institutional Review Board (IRB No. 2016-03-016).

Total 251 patients were initially reviewed, and 223 patients were excluded due to a lack of follow-up records of functional evaluations. Finally, 24 patients who had received rehabilitation were selected in this study and analyzed. The timing of the cranioplasty was determined by neurosurgeons with experience in the suitability of cranioplasty and their operation schedule without any specific protocol, as in previous studies [18,26].

Patients were divided into early and late groups according to the timing of the cranioplasty following decompressive craniectomy, and the cut-off criteria to divide into the early and late groups was 3 months (90 days). In this study, the average time from decompressive craniectomy to cranioplasty was $74.00 \pm 14.52$ days in the early group and $219.08 \pm 131.31$ days in the late group, respectively.

\section{Outcome measures}

The Korean version of the Mini-Mental State Examination (K-MMSE) was used to detect cognitive changes; the Korean version of Modified Barthel Index (K-MBI) was used to detect functional changes; and the Functional Independence Measure (FIM) was assessed from admission to a rehabilitation unit after decompressive craniectomy and at follow-up at least 4 weeks after cranioplasty. The individual subscores for K-MMSE and FIM were also compared between two groups.

\section{Complication}

Neurological and non-neurological complications were analyzed using the patient's electronic medical records in both groups after craniectomy and cranioplasty. We checked for infections, wound breakdown, intracranial hemorrhage, hydrocephalus, bone resorption and pressure ulcer on the scalp, and meningitis-based findings in the cerebrospinal fluid with elevated white blood cell count (normal, $<5$ leukocytes $/ \mu \mathrm{L}$ ) and elevated total protein content (normal, $<45 \mathrm{mg} / \mathrm{dL}$ ) in combination with clinical symptoms including fever, headache, and neck stiffness. Intracranial hemorrhage and hydrocephalus were determined according to CT findings and clinical courses [26].

\section{Statistical analysis}

All statistical analyses were performed using SPSS Statistics ver. 20.0 for Windows (IBM, New York, NY, USA). Baseline numerical data and binomial data between the early and late cranioplasty groups were compared using the Mann-Whitney U test and Pearson chi-square test, respectively. The Mann-Whitney U test was also applied to compare K-MMSE, K-MBI, FIM and their gain of 
two groups. A Spearman's rank correlation analysis was performed to find relationships between the timing of cranioplasty following decompressive craniectomy and K-MMSE, K-MBI, and FIM scores. Numerical data was presented as the mean \pm standard deviation. The $\mathrm{p}$-value less than 0.05 were considered to be significant.

\section{RESULTS}

\section{Baseline characteristics}

As shown in Table 1, age was not different between the early and late groups $(58.75 \pm 15.49$ years vs. $51.42 \pm 13.10$ years, respectively; $\mathrm{p}=0.224$ ). The gender, type of brain lesion, and intervals from onset to craniectomy were also not statistically different between the groups.

Table 1. Baseline characteristics of subjects

\begin{tabular}{|c|c|c|c|}
\hline & Early group $(n=12)$ & Late group $(n=12)$ & p-value \\
\hline Age (yr) & $58.75 \pm 15.49$ & $51.42 \pm 13.10$ & $0.470^{\mathrm{a})}$ \\
\hline Sex & & & $0.673^{\mathrm{b})}$ \\
\hline Male & $7(58.33)$ & $8(66.67)$ & \\
\hline Female & $5(41.67)$ & $4(33.33)$ & \\
\hline \multicolumn{4}{|l|}{ Etiology } \\
\hline Spontaneous & $7(58.33)$ & $5(41.67)$ & $0.414^{\mathrm{b})}$ \\
\hline Traumatic & $5(41.67)$ & $7(58.33)$ & \\
\hline Intervals from onset to DC (day) & $0.25 \pm 0.45$ & $0.50 \pm 0.78$ & $0.551^{\text {a) }}$ \\
\hline Intervals from DC to CP (day) & $74.00 \pm 14.52$ & $219.00 \pm 131.31$ & $<0.001^{\text {a) }}$ \\
\hline
\end{tabular}

Values are presented as mean \pm standard deviations or numbers (\%).

DC, decompressive craniectomy; $\mathrm{CP}$, cranioplasty.

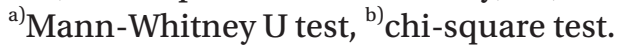

Table 2. Comparisons of cognitive and functional outcomes between early and late groups

\begin{tabular}{|c|c|c|c|}
\hline & Early group $(n=12)$ & Late group $(n=12)$ & p-value ${ }^{\text {a) }}$ \\
\hline Intervals from onset to initial evaluation (day) & $41.17 \pm 31.04$ & $41.17 \pm 20.18$ & 0.523 \\
\hline Intervals from onset to follow-up evaluation (day) & $109.67 \pm 45.90$ & $271.25 \pm 145.30$ & $<0.001^{*}$ \\
\hline \multicolumn{4}{|l|}{ K-MMSE } \\
\hline Initial & $10.75 \pm 10.13$ & $7.17 \pm 9.07$ & 0.463 \\
\hline Follow-up & $15.25 \pm 10.96$ & $6.08 \pm 9.28$ & 0.053 \\
\hline Gain & $4.50 \pm 7.49$ & $-1.08 \pm 3.65$ & $0.019^{*}$ \\
\hline \multicolumn{4}{|l|}{ K-MBI } \\
\hline Initial & $20.42 \pm 20.92$ & $16.00 \pm 17.72$ & 0.605 \\
\hline Follow-up & $29.25 \pm 27.13$ & $17.75 \pm 20.32$ & 0.121 \\
\hline Gain & $8.83 \pm 10.29$ & $1.75 \pm 21.14$ & 0.138 \\
\hline \multicolumn{4}{|l|}{ FIM } \\
\hline Initial & $42.75 \pm 23.64$ & $36.17 \pm 18.60$ & 0.635 \\
\hline Follow-up & $52.17 \pm 25.98$ & $36.00 \pm 18.87$ & $0.025^{*}$ \\
\hline Gain & $9.42 \pm 15.96$ & $-0.17 \pm 17.86$ & $0.042^{*}$ \\
\hline
\end{tabular}

Values are presented as mean \pm standard deviations.

K-MMSE, Korean version of Mini-Mental State Examination; K-MBI, Korean version of Modified Barthel Index; FIM, Functional Independence Measure.

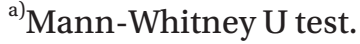

${ }^{*} \mathrm{p}<0.05$. 


\section{Cognitive and functional outcomes}

The duration from onset to the initial evaluation was not different between the early and late groups (41.17 \pm 31.04 days vs. $41.17 \pm 20.18$ days; $\mathrm{p}=0.523$ ), but the duration from onset to follow-up was different between two groups ( $109.67 \pm 45.90$ days vs. $271.25 \pm 145.30$ days, respectively; $\mathrm{p}<0.001$ ) (Table 2).

The initial K-MMSE scores after decompressive craniectomy were not different between groups $(10.75 \pm 10.13$ vs. 7.17 $\pm 9.07 ; \mathrm{p}=0.463)$, but gain score of K-MMSE in the

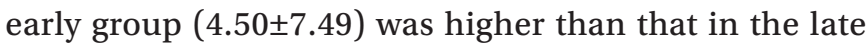
group $(-1.08 \pm 3.65, \mathrm{p}=0.019)$ (Table 2$)$. The initial, followup and gain K-MBI scores, and the initial FIM scores were not different between two groups. However, the followup and gain FIM scores in the early group $(52.17 \pm 25.98$ and $9.42 \pm 15.96$, respectively) were significantly higher than those in the late group $(36.00 \pm 18.87$ and $-0.17 \pm 17.86$;

Table 3. Comparisons of the Korean version of the MiniMental State Examination subscores between early and late groups

\begin{tabular}{|cccc}
\hline & $\begin{array}{c}\text { Early group } \\
(\mathbf{n}=12)\end{array}$ & $\begin{array}{c}\text { Late group } \\
(\mathbf{n}=12)\end{array}$ & p-value ${ }^{\mathrm{a})}$ \\
\hline Orientation (10) & & & \\
\hline Initial & $3.17 \pm 4.00$ & $2.50 \pm 3.45$ & 0.815 \\
\hline Follow-up & $5.33 \pm 3.92$ & $2.17 \pm 3.21$ & 0.051 \\
\hline Gain & $2.17 \pm 2.98$ & $-0.33 \pm 0.89$ & $0.004^{*}$ \\
\hline Memory registration (3) & & \\
\hline Initial & $1.42 \pm 1.50$ & $1.08 \pm 1.37$ & 0.662 \\
\hline Follow-up & $1.83 \pm 1.47$ & $1.17 \pm 1.27$ & 0.176 \\
\hline Gain & $0.42 \pm 1.24$ & $0.08 \pm 1.31$ & 0.767 \\
\hline Attention (5) & & & \\
\hline Initial & $0.75 \pm 1.36$ & $0.50 \pm 1.00$ & 0.712 \\
\hline Follow-up & $1.58 \pm 2.02$ & $0.75 \pm 1.48$ & 0.330 \\
\hline Gain & $0.83 \pm 1.85$ & $0.25 \pm 0.62$ & 0.468 \\
\hline Memory recall (3) & & & \\
\hline Initial & $1.00 \pm 1.20$ & $0.33 \pm 0.89$ & 0.140 \\
\hline Follow-up & $1.25 \pm 1.36$ & $0.33 \pm 0.89$ & 0.086 \\
\hline Gain & $0.25 \pm 0.75$ & $0 \pm 0$ & 0.217 \\
\hline Language (9) & & & \\
\hline Initial & $3.83 \pm 3.76$ & $2.42 \pm 3.03$ & 0.363 \\
\hline Follow-up & $6.00 \pm 3.79$ & $2.67 \pm 3.11$ & $0.015^{*}$ \\
\hline Gain & $2.17 \pm 2.59$ & $0.25 \pm 1.86$ & $0.016^{*}$ \\
\hline
\end{tabular}

Values are presented as mean \pm standard deviation.

${ }^{\text {a) } M a n n-W h i t n e y ~ U}$ test.

${ }^{*} \mathrm{p}<0.05$. $\mathrm{p}=0.025$ and $\mathrm{p}=0.042$, respectively) (Table 2 ).

Some of the K-MMSE subscores and FIM subcategories were different between two groups (Tables 3, 4). Among the K-MMSE subscores, the gains in the orientation and language subscores were higher in the early group (2.17 \pm 2.98 and $2.17 \pm 2.59$, respectively) than in the late group $(-0.33 \pm 0.89$ and $0.25 \pm 1.86 ; \mathrm{p}=0.004$ and $\mathrm{p}=0.016$, respectively) (Table 3 ). The gains for self-care, transfer and locomotor functions in FIM subcategories were significantly higher in the early group (5.83 \pm 9.99 and $5.75 \pm 6.00$, respectively) than in the late group $(-0.33 \pm 4.96$ and $0.58 \pm$ $3.50 ; \mathrm{p}=0.036$ and $\mathrm{p}=0.009$, respectively), and the followup score for the cognition was higher in the early group than in the late group $(22.33 \pm 10.37$ vs. $13.17 \pm 8.35$, respectively; $\mathrm{p}=0.023$ ) (Table 4 ).

In addition, we found a moderate negative correlation (Spearman's correlation coefficient $>0.5 ; \mathrm{p}<0.05$ ) between the timing of cranioplasty following decompressive craniectomy and the gain in the K-MMSE total score, orientation and language subscores of K-MMSE, and transfer and locomotion subscores of FIM (Table 5).

Table 4. Comparisons of Functional Independence Measure subscores between early and late groups

\begin{tabular}{lccl}
\hline & $\begin{array}{c}\text { Early group } \\
(\mathbf{n}=12)\end{array}$ & $\begin{array}{c}\text { Late group } \\
(\mathbf{n}=12)\end{array}$ & p-value $^{\mathbf{a})}$ \\
\hline Self-care & & & \\
\hline Initial & $12.25 \pm 7.44$ & $11.33 \pm 6.15$ & 0.896 \\
\hline Follow-up & $18.08 \pm 11.06$ & $11.00 \pm 4.99$ & 0.071 \\
\hline Gain & $5.83 \pm 9.99$ & $-0.33 \pm 4.96$ & $0.036^{*}$ \\
\hline Sphincter control & & & \\
\hline Initial & $7.17 \pm 5.75$ & $5.25 \pm 3.84$ & 0.392 \\
\hline Follow-up & $8.08 \pm 5.05$ & $7.17 \pm 5.36$ & 0.634 \\
\hline Gain & $0.92 \pm 4.81$ & $1.92 \pm 5.82$ & 0.992 \\
\hline Transfer and locomotion & & \\
\hline Initial & $7.42 \pm 3.26$ & $7.75 \pm 3.36$ & 0.795 \\
\hline Follow-up & $13.17 \pm 7.48$ & $8.33 \pm 3.84$ & 0.110 \\
\hline Gain & $5.75 \pm 6.00$ & $0.58 \pm 3.50$ & $0.009^{*}$ \\
\hline Cognition & & & \\
\hline Initial & $15.92 \pm 10.17$ & $12.25 \pm 8.07$ & 0.428 \\
\hline Follow-up & $22.33 \pm 10.37$ & $13.17 \pm 8.35$ & $0.023^{*}$ \\
\hline Gain & $6.42 \pm 9.05$ & $0.92 \pm 3.23$ & 0.052 \\
\hline
\end{tabular}

Values are presented as mean \pm standard deviations.

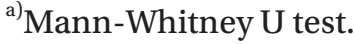

${ }^{*} \mathrm{p}<0.05$. 
Table 5. Correlation between the operation interval and the cognitive and functional outcomes

\begin{tabular}{|ccc|}
\hline & $\begin{array}{c}\text { Spearman's } \\
\text { correlation } \\
\text { coefficient }\end{array}$ & p-value \\
\hline Total K-MMSE score & -0.560 & $0.004^{*}$ \\
\hline Orientation subscore & -0.569 & $0.004^{*}$ \\
\hline Language subscore & -0.598 & $0.002^{*}$ \\
\hline Total FIM score & -0.360 & 0.084 \\
\hline Self-care subscore & -0.436 & $0.033^{*}$ \\
Transfer and locomotion & -0.503 & $0.012^{*}$ \\
subscore & & \\
\hline Cognition subscore & -0.282 & 0.182 \\
\hline
\end{tabular}

K-MMSE, Korean version of Mini-Mental State Examination; K-MBI, Korean version of Modified Barthel Index; FIM, Functional Independence Measure. ${ }^{*} \mathrm{p}<0.05$.

\section{Complication}

After craniectomy, several complications were identified in both groups, including pneumonia, pseudomembranous colitis, urinary tract infection, and seizure, which were treated before cranioplasty and did not affect the timing of cranioplasty, and the incidence was not different between the early and the late groups (Table 6). After cranioplasty, one patient in the early group (8.3\%) showed an occipital scalp sore. However, no critical complications, including infection, wound breakdown, intracranial hemorrhage, hydrocephalus and bone resorption, were found in both groups after cranioplasty.

\section{DISCUSSION}

The optimal timing to perform cranioplasty after decompressive craniectomy is particularly important in a rehabilitation unit because most stroke or TBI patients, who are transferred into the department of rehabilitation medicine after decompressive craniectomy, are considered to receive cranioplasty, and this additional operation and its concomitant complications may affect the hospital stay, prognosis, and functional outcomes of patients. According to previous studies, cranioplasty is commonly conducted 3 to 6 months after craniectomy due to risks of infection or unresolved brain swelling [10], and 3 months are most commonly used to define early cranioplasty $[4,6,11,20,26,28]$. Therefore, we determined
Table 6. Postoperative complications after craniectomy and before cranioplasty in early and late groups

\begin{tabular}{llll}
\hline & $\begin{array}{c}\text { Early group } \\
(\mathbf{n = 1 2 )}\end{array}$ & $\begin{array}{c}\text { Late group } \\
(\mathbf{n}=12)\end{array}$ & $\begin{array}{c}\text { p- } \\
\text { value }^{\mathbf{a})}\end{array}$ \\
\hline Pneumonia & $3(25.00)$ & $3(25.00)$ & 1.000 \\
$\begin{array}{l}\text { Pseudomembranous } \\
\text { colitis }\end{array}$ & $2(16.67)$ & $0(0)$ & 0.478 \\
Urinary tract infection & $0(0)$ & $1(8.33)$ & 1.000 \\
Seizure & $1(8.33)$ & $0(0)$ & 1.000 \\
\hline
\end{tabular}

Values are presented in numbers (\%).

${ }^{\text {a) }}$ Fisher exact test.

the criteria for early decompression to 3 months. The advantages of early cranioplasty were reported in several studies, including shorter dissection and operation time [22,29], fewer blood loss [22], cost reduction [29], and better functional outcomes $[10,16,26]$. However, the disadvantages of early cranioplasty have also been reported, including epidural or subdural hematoma, wound healing disturbance, hydrocephalus, infection and bone resorption [17-19].

We found that cognitive functions, especially orientation and language function, self-care, transfer and locomotion improved in patients who received early cranioplasty more than in patients with late cranioplasty (Tables 2-4). Cranioplasty following decompressive craniectomy increases cerebral blood flow in major intracranial arteries in both hemispheres, and as a result, significant improvement after cranioplasty in language function and activities of daily living were also previously reported [30-32]. The cranioplasty also increased the glucose metabolism of the injured hemisphere and cerebrovascular reserve capacity in both hemispheres, as shown in positron emission tomography and Doppler ultrasonography [9], and another previous studies using functional MRI reported that the auditory response and resting-state networks recovered after cranioplasty and were well correlated with functional recovery [33]. In addition, Song et al. [11] found that early cranioplasty improved cerebral blood flow of the contralateral side of middle cerebral artery as well as the ipsilateral side of middle cerebral and internal carotid arteries. In our study, cerebral blood flow and glucose metabolism may have decreased in patients after decompressive craniectomy and persisted more in the late cranioplasty group. Therefore, their cognitive and functional improvements are also delayed more 
than for the early cranioplasty group. No previous studies have analyzed the change in the transfer and locomotion function according to the timing of the cranioplasty, but we found that the transfer and locomotion function significantly improved in the early cranioplasty group but not in the late cranioplasty group ( $5.75 \pm 6.00$ vs. $0.58 \pm 3.50$; $\mathrm{p}=0.009$ ) (Table 4). The improvement in the transfer and locomotion, as well as the cognitive improvement, is important for patients' quality of life and economic wellbeing by reducing the burden of caring and the length of the hospital stay.

Bender et al. [26] reported that patients who received an early cranioplasty ( $<86$ days) had better functional outcomes, as measured using the Barthel Index and FIM, than those who received a late cranioplasty. However, they did not analyze the individual subscores for each assessment tool. In our study, the gain scores of the total FIM, self-care, transfer and locomotor subcategories, and the follow-up scores of the cognition subcategory significantly improved further in the early cranioplasty group than those in the late group. Otherwise, K-MBI was not different between two groups. A previous study reported ceiling effects of the Barthel Index in stroke patients with higher score [34], and high standard deviation with a small number of subjects might mask the difference in the K-MBI score between two groups (Table 2).

According to previous studies, the incidence of complications after cranioplasty vary from $12 \%$ to $33 \%$ $[4,21,35,36]$. Some studies have reported that the timing of the cranioplasty is a predictor of postoperative complications [17-19]. However, in our study, we found only one patient $(8.3 \%)$ who had a minor problem with scalp sore after cranioplasty.

The study has limitations since the analysis was retrospective with patients from a single center. Although the incidence of complications during pre-cranioplasty period was not different between the early and late groups (Table 6), any medical and functional conditions that were not identified in medical records may affect the timing of cranioplasty operation and follow-up results. In addition, small sample size might result in a lower statistical significance. Further prospective and multi-center study will strengthen the usefulness of early cranioplasty after decompressive craniectomy as well as the relationship between the timing of cranioplasty and the postoperative complications in patients with traumatic brain

\section{injury or stroke.}

In conclusion, early cranioplasty after decompressive craniectomy in patients with traumatic brain injury or spontaneous cerebral hemorrhage might be helpful to restore cognitive impairments, especially orientation and language ability. It also has potential benefits to functional impairments for self-care and mobility.

\section{CONFLICT OF INTEREST}

No potential conflicts of interest relevant to this article were reported.

\section{ACKNOWLEDGMENTS}

This work was carried out with the support of the 'Cooperative Research Program for Agriculture Science \& Technology Development (Project No. PJ010244032015)' Rural Development Administration, Republic of Korea.

\section{REFERENCES}

1. Hofmeijer J, Kappelle LJ, Algra A, Amelink GJ, van Gijn J, van der Worp HB, et al. Surgical decompression for space-occupying cerebral infarction (the Hemicraniectomy After Middle Cerebral Artery infarction with Life-threatening Edema Trial [HAMLET]): a multicentre, open, randomised trial. Lancet Neurol 2009;8:32633.

2. Juttler E, Bosel J, Amiri H, Schiller P, Limprecht R, Hacke W, et al. DESTINY II: DEcompressive Surgery for the Treatment of malignant INfarction of the middle cerebral arterY II. Int J Stroke 2011;6:79-86.

3. Vahedi K, Vicaut E, Mateo J, Kurtz A, Orabi M, Guichard JP, et al. Sequential-design, multicenter, randomized, controlled trial of early decompressive craniectomy in malignant middle cerebral artery infarction (DECIMAL Trial). Stroke 2007;38:2506-17.

4. Chang V, Hartzfeld P, Langlois M, Mahmood A, Seyfried D. Outcomes of cranial repair after craniectomy. J Neurosurg 2010;112:1120-4.

5. Aarabi B, Hesdorffer DC, Ahn ES, Aresco C, Scalea TM, Eisenberg HM. Outcome following decompressive craniectomy for malignant swelling due to severe head injury. J Neurosurg 2006;104:469-79.

6. Chibbaro S, Di Rocco F, Mirone G, Fricia M, Makiese 
O, Di Emidio P, et al. Decompressive craniectomy and early cranioplasty for the management of severe head injury: a prospective multicenter study on $147 \mathrm{pa}$ tients. World Neurosurg 2011;75:558-62.

7. Jaeger M, Soehle M, Meixensberger J. Effects of decompressive craniectomy on brain tissue oxygen in patients with intracranial hypertension. J Neurol Neurosurg Psychiatry 2003;74:513-5.

8. Dujovny M, Fernandez P, Alperin N, Betz W, Misra M, Mafee M. Post-cranioplasty cerebrospinal fluid hydrodynamic changes: magnetic resonance imaging quantitative analysis. Neurol Res 1997;19:311-6.

9. Winkler PA, Stummer W, Linke R, Krishnan KG, Tatsch K. Influence of cranioplasty on postural blood flow regulation, cerebrovascular reserve capacity, and cerebral glucose metabolism. J Neurosurg 2000;93:5361.

10. Cho KC, Park SC, Choe IS, Seo DH. Safety and efficacy of early cranioplasty after decompressive craniectomy in traumatic brain injury patients. J Korean Neurotraumatol Soc 2011;7:74-7.

11. Song J, Liu M, Mo X, Du H, Huang H, Xu GZ. Beneficial impact of early cranioplasty in patients with decompressive craniectomy: evidence from transcranial Doppler ultrasonography. Acta Neurochir (Wien) 2014;156:193-8.

12. Yoshida K, Furuse M, Izawa A, Iizima N, Kuchiwaki $\mathrm{H}$, Inao S. Dynamics of cerebral blood flow and metabolism in patients with cranioplasty as evaluated by 133Xe CT and 31P magnetic resonance spectroscopy. J Neurol Neurosurg Psychiatry 1996;61:166-71.

13. Dujovny M, Aviles A, Agner C, Fernandez P, Charbel FT. Cranioplasty: cosmetic or therapeutic? Surg Neurol 1997;47:238-41.

14. Erdogan E, Duz B, Kocaoglu M, Izci Y, Sirin S, Timurkaynak E. The effect of cranioplasty on cerebral hemodynamics: evaluation with transcranial Doppler sonography. Neurol India 2003;51:479-81.

15. Kuo JR, Wang CC, Chio CC, Cheng TJ. Neurological improvement after cranioplasty: analysis by transcranial doppler ultrasonography. J Clin Neurosci 2004;11: 486-9.

16. Liang W, Xiaofeng Y, Weiguo L, Gang S, Xuesheng Z, Fei C, et al. Cranioplasty of large cranial defect at an early stage after decompressive craniectomy performed for severe head trauma. J Craniofac Surg 2007;
18:526-32.

17. Schuss P, Vatter H, Marquardt G, Imohl L, Ulrich CT, Seifert V, et al. Cranioplasty after decompressive craniectomy: the effect of timing on postoperative complications. J Neurotrauma 2012;29:1090-5.

18. Borger V, Schuss P, Kinfe TM, Vatter H, Guresir E. Decompressive craniectomy for stroke: early cranioplasty is a predictor for postoperative complications. World Neurosurg 2016;92:83-8.

19. Xu H, Niu C, Fu X, Ding W, Ling S, Jiang X, et al. Early cranioplasty vs. late cranioplasty for the treatment of cranial defect: a systematic review. Clin Neurol Neurosurg 2015;136:33-40.

20. Archavlis E, Carvi Y Nievas M. The impact of timing of cranioplasty in patients with large cranial defects after decompressive hemicraniectomy. Acta Neurochir (Wien) 2012;154:1055-62.

21. Beauchamp KM, Kashuk J, Moore EE, Bolles G, Rabb C, Seinfeld J, et al. Cranioplasty after postinjury decompressive craniectomy: is timing of the essence? J Trauma 2010;69:270-4.

22. Chun HJ, Yi HJ. Efficacy and safety of early cranioplasty, at least within 1 month. J Craniofac Surg 2011;22: 203-7.

23. Carvi Y Nievas MN, Hollerhage HG. Early combined cranioplasty and programmable shunt in patients with skull bone defects and CSF-circulation disorders. Neurol Res 2006;28:139-44.

24. Yadla S, Campbell PG, Chitale R, Maltenfort MG, Jabbour P, Sharan AD. Effect of early surgery, material, and method of flap preservation on cranioplasty infections: a systematic review. Neurosurgery 2011; 68:1124-30.

25. Piedra MP, Thompson EM, Selden NR, Ragel BT, Guillaume DJ. Optimal timing of autologous cranioplasty after decompressive craniectomy in children. J Neurosurg Pediatr 2012;10:268-72.

26. Bender A, Heulin S, Rohrer S, Mehrkens JH, Heidecke V, Straube A, et al. Early cranioplasty may improve outcome in neurological patients with decompressive craniectomy. Brain Inj 2013;27:1073-9.

27. Huang YH, Lee TC, Yang KY, Liao CC. Is timing of cranioplasty following posttraumatic craniectomy related to neurological outcome? Int J Surg 2013;11:886-90.

28. De Bonis P, Frassanito P, Mangiola A, Nucci CG, Anile C, Pompucci A. Cranial repair: how complicated is 
filling a "hole"? J Neurotrauma 2012;29:1071-6.

29. Piedra MP, Nemecek AN, Ragel BT. Timing of cranioplasty after decompressive craniectomy for trauma. Surg Neurol Int 2014;5:25.

30. Corallo F, Marra A, Bramanti P, Calabro RS. Effect of cranioplasty on functional and neuropsychological recovery after severe acquired brain injury: fact or fake? Considerations on a single case. Funct Neurol 2014;29:273-5.

31. Jelcic N, Della Puppa A, Mottaran R, Cecchin D, Manara R, Dam M, et al. Case series evidence for improvement of executive functions after late cranioplasty. Brain Inj 2013;27:1723-6.

32. Paredes I, Castano AM, Cepeda S, Alen JA, Salvador E, Millan JM, et al. The effect of cranioplasty on cerebral hemodynamics as measured by perfusion computed tomography and doppler ultrasonography. J Neu- rotrauma 2016;33:1586-97.

33. Voss HU, Heier LA, Schiff ND. Multimodal imaging of recovery of functional networks associated with reversal of paradoxical herniation after cranioplasty. Clin Imaging 2011;35:253-8.

34. Dromerick AW, Edwards DF, Diringer MN. Sensitivity to changes in disability after stroke: a comparison of four scales useful in clinical trials. J Rehabil Res Dev 2003;40:1-8.

35. Moreira-Gonzalez A, Jackson IT, Miyawaki T, Barakat K, DiNick V. Clinical outcome in cranioplasty: critical review in long-term follow-up. J Craniofac Surg 2003; 14:144-53.

36. Matsuno A, Tanaka H, Iwamuro H, Takanashi S, Miyawaki S, Nakashima M, et al. Analyses of the factors influencing bone graft infection after delayed cranioplasty. Acta Neurochir (Wien) 2006;148:535-40. 